\title{
Konservasi Preventif Karya Seni Lukis bagi Mahasiswa Seni
}

\author{
Irma Damajanti
}

KK Ilmu Seni \& Estetika-FSRD -Institut Teknologi Bandung

\begin{abstract}
The book of "The Introduction of Preventive Conservation on Painting for Visual Art Students" explains how to apply preventive conservation techniques for objects of culture and collections, especially paintings. It is said that preventive conservation optimizes environmental conditions to which objects and collections are housed. By controlling light and ultraviolet radiation, humidity and temperature, biological pets, dust and pollutants, we can prevent damages and decays of the paintings. In addition, preventive conservation also means in ensuring that good handling, transportation, storage and displaying techniques are used at all times. Thus, applying preventive methods can prolong and protect the life of artworks for the future.

Yet, although the Introduction of Preventive Conservation on Painting provides information on how to give care of paintings as objects of culture and collections, it is important to understand that all except the simplest conservation treatments should be taken by trained conservators. Thus, active conservation treatment is a response skill to the damaging process of cultural artifacts, a highly skilled field that requires extensive knowledge on the use of chemicals and rigorous technical procedures.
\end{abstract}

Keywords: Conservation; Handling Object; Paint Layer; Preventive; Support Layer.

\section{$1 \quad$ Karya Senilukis sebagai Artifak Jejak Kebudayaan}

Sejak dimulainya Abad Pencerahan (Enlightment) di Eropa, manusia modern mulai menyadari pentingnya ilmu pengetahuan. Bangsa Eropa kemudian mulai menelaah semua artefak alam dan kebudayaan demi terjawabnya semua bentuk kenyataan alam dan segala bentuk kebudayaan yang telah dibangun manusia. Kesadaran tersebut kemudian menjadi melembaga ke dalam suatu kesadaran untuk menyimpan (collecting) dan memamerkan semua bentuk temuan (alam dan hasil budaya manusia) dalam satu institusi yang dinamakan museum.

Dalam institusi museum berbagai artifak ditelaah dan diinformasikan kepada publik demi perkembangan pengetahuan. Perkembangan museum kemudian bergeser dari hanya sekedar menampilkan "informasi" ke dalam suatu 
kesadaran segmentasi akan aspek "keindahan" sebuah artefak, sehingga untuk memisahkan faktor tersebut kemudian dibentuklah sebuah lembaga yang dinamakan galeri. Galeri mengelola koleksi yang menampilkan karya-karya seni hasil kreasi manusia (seniman).

Seni lukis sebagai salah satu hasil karya manusia, menjadi suatu artefak budaya yang sangat penting dalam perjalanan kebudayaan manusia. Pada masa sebelum diciptakannya fotografi, seni lukis menjadi andalan informasi penting dalam menggambarkan kenyataan alam dan lingkungannya. Sehingga keberadaan seni lukis menjadi tradisi; selain aspek informasi juga menampilkan dimensi lain seperti estetik dan cara pandang manusia. Seni lukis menjadi salah satu bukti peradaban yang perlu direkam, diinterpretasikan dan terus dipelihara dalam semangat ilmu pengetahuan dan pencapaian peradaban.

Dari seluruh cabang seni rupa (visual arts), seni lukis adalah yang paling banyak dipraktikkan. Anak-anak dan para manula, seniman profesional dan para amatir, orang-orang yang sakit dan sehat — semuanya melukis, kelihatannya lebih untuk kepuasan pribadi, tidak selalu untuk orang lain. Tentu saja ada banyak alasan mengapa seni lukis lebih banyak menarik peminat dibanding seni patung misalnya. Salah satu di antaranya adalah: fleksibilitas dan potensi yang beraneka ragam dari seni lukis, khususnya dalam lukisan cat minyak. [1]

Lukisan pada dasarnya terdiri dari setidaknya 2 lapisan, yaitu:

1. lapisan penyokong (support layer) tempat lapisan gambar (image) berada —dapat berupa kanvas, panil kayu, atau masonite (sejenis hardboard); dan

2. lapisan gambar (image layer) —cat minyak, cat akrilik atau kombinasi cat dengan material lainnya.

Jika ikatan di antara kedua lapisan tersebut lemah, setiap gerakan yang terjadi pada penyokong akan mengakibatkan kerusakan pada lapisan cat.

Sebagian besar lukisan lebih kompleks lagi dan memiliki lebih banyak bagian dalam strukturnya. Sebuah lukisan tradisional di atas kanvas umumnya akan memiliki:

1. dempulan —dalam banyak kasus kanvas didempul dengan lapisan lem;

2. cat dasar atau lapisan dasar;

3. lapisan cat (lukisan) atau image layer;

4. lapisan pernis (varnish layer); dan

5. alat bantu yang memberikan dukungan secara fisik untuk menyokong lapisan. 
Maraknya bentuk-bentuk pengkoleksian karya seni khususnya seni lukis menunjukkan gairah yang positif terhadap tumbuhnya apresiasi seni masyarakat terhadap produk seni. Namun hal ini saja tidak cukup bila tidak ditunjang oleh kondisi karya yang layak dalam perspektif konservasi (pemeliharaannya). Sebagai contoh adalah kondisi yang terjadi di lingkungan Progrsm Studi Seni Rupa FSRD-ITB, kebanyakan mahasiswa meletakkan karya-karya studinya begitu saja tanpa mempertimbangkan faktor-faktor yang mungkin dapat mengakibatkan terjadinya kerusakan pada karya. Hal tersebut disebabkan karena ketidakpahaman mahasiswa akan pentingnya memperlakukan karya seni sebagai salah satu artifak budaya dengan tepat, serta masih belum populernya kegiatan konservasi seni di Indonesia.

Pengetahuan tentang konservasi karya seni sudah saatnya diajarkan pada mahasiswa seni rupa sebagai bagian integral keprofesiannya agar menjadi kesadaran akan pentingnya memelihara karya secara baik dan terjaga. Selain itu pengembangan pemikiran yang berkaitan dengan konservasi seni perlu dilakukan sebagai upaya positif dalam meningkatkan apresiasi masyarakat terhadap bidang tersebut.

Pengertian konservasi:

All actions aimed at safeguarding cultural material for the future. Its purpose is to study, record, retain and restore the culturally significant qualities of an object with the least possible intervention.

Sedangkan konservasi preventif (preventive conservation) memiliki pengertian:

All actions undertaken to prevent the deterioration of cultural materials and collection. [2]

\section{Permasalahan Konsevasi Lukisan di Lingkungan FSRD ITB}

\subsection{Kondisi Karya-karya Seni Lukis}

Berdasarkan kategorisasi jenis museum, menurut Museums Australia Inc., Galeri Soemardja ITB yang saat ini berada di bawah pengelolaan Fakultas Seni Rupa dan Desain ITB merupakan sebuah museum perguruan tinggi (university museum), jenis museum yang berada di bawah struktur keseluruhan dari suatu perguruan tinggi dan memiliki fungsi untuk mendukung program-program pengajaran dan penelitian, menyumbangkan kehidupan kultural pada lingkungan kampus dan memperkuat jaringan kerja sama antara perguruan tinggi dan komunitas yang lebih luas. [3] 
Sesuai dengan fungsinya tersebut, Galeri Soemardja ITB banyak menyimpan koleksi-koleksi seni di dalamnya, khususnya lukisan. Namun, berdasarkan hasil observasi langsung, sampai saat ini Galeri Soemardja ITB belum memiliki ruangan khusus untuk menyimpan koleksi-koleksi tersebut. Hal tersebut menyebabkan sebagian besar karya dibiarkan tersandar di dinding-dinding selasar Galeri (Gambar.1). Akibatnya, kerusakan-kerusakan yang tak terhindarkan pun terjadi pada hampir sebagian besar koleksi, terutama yang memang sudah berusia relatif tua. Hal yang sama pun terjadi di Studio Seni Lukis FSRD-ITB, dengan mudah ditemukan karya-karya lukis hasil studi mahasiswa yang disimpan atau diletakkan begitu saja, tanpa memperhitungkan faktor keamanan karya.

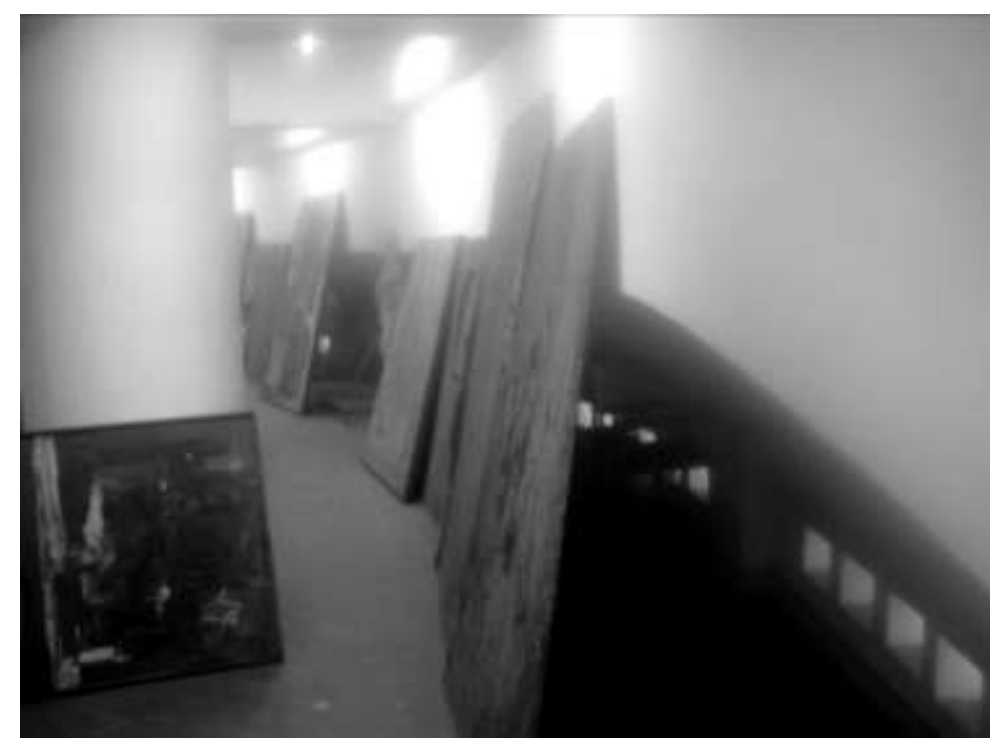

Gambar 1 Penyimpanan koleksi lukisan di ruang Galeri Soemardja.

Beberapa jenis kerusakan yang terjadi pada lukisan koleksi Galeri Soemardja ITB yang berhasil didata antara lain:

1. Struktur lukisan yang menjadi rapuh karena berbagai faktor penyebab, seperti karena dimakan usia, hama serangga, atau cuaca, seperti kanvas yang menjadi robek dan terlepas dari stretcher (Gambar. 2).

2. Struktur lukisan, khususnya lapisan gambar rusak karena kelembaban relatif yang tidak stabil (Gambar. 3).

3. Lukisan rusak karena tumbuh dan berkembangnya jamur yang dipicu oleh ketakstabilan kelembaban relatif. 
4. Ketidak hati-hatian dalam penyimpanan mengakibatkan struktur lukisan menjadi rusak.

5. Terkelupasnya lapisan cat (paint layer) pada lukisan.

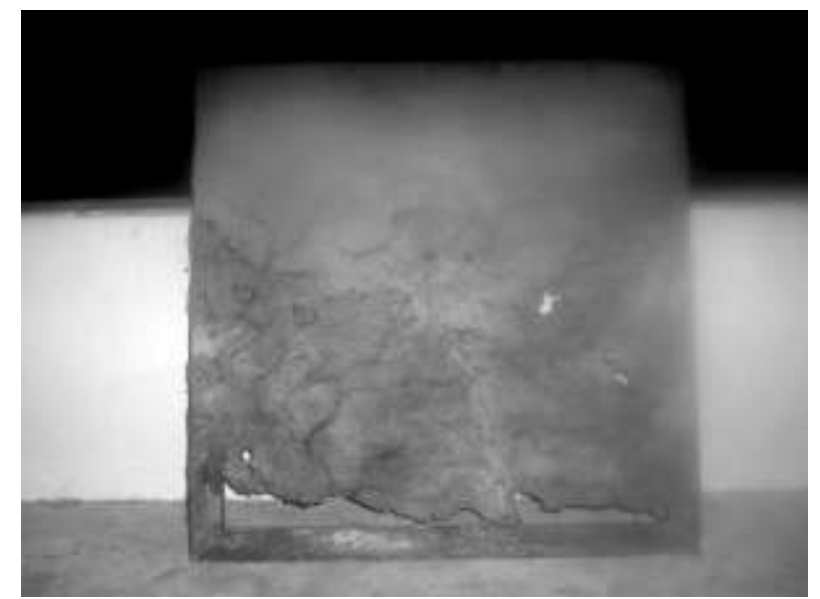

Gambar 2 Kanvas lukisan yang terobek dari stretcher.

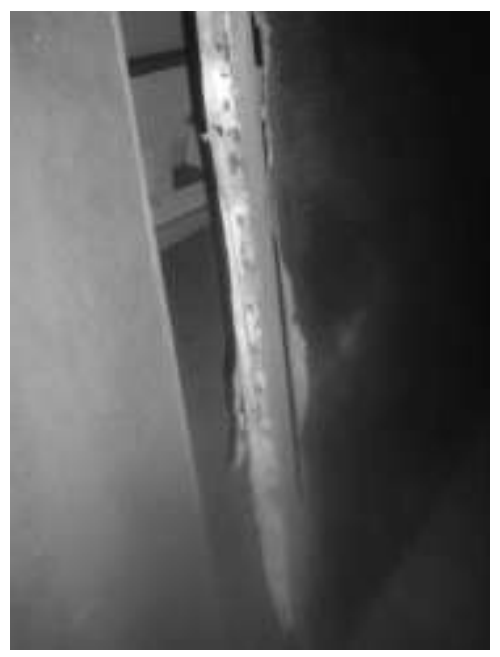

Gambar 3 Struktur lukisan yang rusak karena lembab.

\subsection{Faktor-Faktor Penyebab Kerusakan}

Terdapat sejumlah faktor yang dapat menjadi penyebab kerusakan pada koleksi lukisan di antaranya:

1. Belum tumbuhnya sikap menghargai karya seni sebagai artifak budaya. 
2. Kurangnya pengetahuan tentang bidang konservasi seni pada umumnya, konservasi preventif khususnya.

3. Adanya anggapan bahwa pemeliharaan karya adalah bagian dari tugas seorang kurator atau konservator (pengelola galeri), bukan tugas seorang seniman.

4. Kondisi alam Indonesia yang beriklim tropis dengan tingkat curah hujan yang tinggi menyebabkan tidak stabilnya temperatur dan tingkat kelembaban, yang dapat mengakibatkan tumbuh dan berkembangnya jamur dan hama serangga yang merusak struktur dan penampilan (appearance) lukisan.

\subsection{Metoda Pemecahan}

Pada dasarnya ada dua bentuk kegiatan konservasi, yaitu konservasi preventif (preventive conservation) dan konservasi aktif (active conservation). Konservasi preventif lebih bersifat antisipasi, berupa kegiatan pencegahan dan pemeliharaan kondisi karya seni. Konservasi preventif ini juga lebih merupakan upaya untuk membangun sikap kepedulian terhadap artifak-artifak budaya, termasuk karya seni lukis. Prosedur-prosedur yang dilaksanakan dalam konservasi preventif relatif sederhana dan lebih bersifat manual sehingga mudah untuk diterapkan dan tidak memerlukan keakhlian khusus. Di samping itu, konservasi preventif juga relatif ekonomis.

Sedangkan konservasi aktif lebih bersifat rehabilitatif yaitu perbaikan terhadap kerusakan-kerusakan. Berbeda dengan konsevasi preventif, konservasi aktif menuntut keakhlian khusus karena seringkali melibatkan bahan-bahan kimiawi dan prosedur teknis yang rumit. Hanya konservator yang terlatih, dengan peralatan dan bahan yang tepat, yang mampu menangani konservasi aktif.

Dari hasil inventarisasi masalah dan analisa faktor-faktor penyebab di atas maka pemecahan masalah yang dianggap paling sesuai dan memungkinkan untuk dilakukan pada kondisi saat ini adalah dengan memperkenalkan pengetahuan tentang konservasi preventif terhadap para mahasiswa seni. Jenis konservasi ini dipilih karena sifatnya yang lebih antisipatif, berupa upaya-upaya pencegahan dengan teknis yang mudah, hemat, efisien, namun efektif untuk menghindari atau setidaknya mengurangi kerusakan pada karya. Konservasi preventif juga tidak menuntut keakhlian khusus.

\section{$3 \quad$ Konservasi Preventif Karya Seni Lukis}

Pengetahuan konservasi preventif (preventive conservation) pada karya lukis meliputi: 
1. pengenalan struktur dan bagian-bagian dari beragam jenis lukisan;

2. pemahaman sumber-sumber kerusakan yang mungkin menimpa lukisan;

3. pengetahuan membingkai dan menggantung sebuah lukisan untuk memastikan perlindungan yang layak dari kerusakan.

\subsection{Kerusakan pada Lukisan dan Teknik Penanggulangannya}

Kondisi lukisan yang memburuk disebabkan oleh kerusakan dan aktivitas kimiawi — umumnya gabungan dari keduanya — sebagai berikut:

1. Kerusakan Fisik; kerusakan ini jelas terlihat, termasuk di antaranya: sobekan dan retakan, rusaknya lapisan pernis dan cat karena gerakan yang ditimbulkan penyokongnya, pernis yang lembab karena suhu tinggi menyebabkan debu dan kotoran menempel secara permanen pada lukisan, serangan serangga, dll.

2. Unsur Kimiawi; kerusakan kimiawi pada lukisan, di antaranya: perubahan warna dan pudarnya pigmen karena tertimpa cahaya atau radiasi sinar ultra violet, reaksi antar komponen lukisan yang tidak cocok, serangan jamur, dll.

\subsection{Memahami Cara Membawa Lukisan (Handling Paintings)}

Dikarenakan sebuah lukisan memiliki struktur yang kompleks, penting bagi mahasiswa untuk memahami prosedur penanganan yang tepat, seperti:

1. Sebelum memindahkan lukisan, beberapa hal yang harus diperhatikan antara lain: pastikan agar tidak ada cat yang terkelupas, tidak ada bagian bingkai yang terlepas, dan karya aman di bingkainya; jangan memegang kanvas dan permukaan lukisan secara langsung; selalu memegang lukisan pada titik dimana bingkai kokoh.

2. Jika menggantung lukisan, pastikan bahwa alat-alat penggantung dan dinding dimana lukisan akan dipasang dalam kondisi aman.

3. Untuk memindahkan lukisan yang dilindungi kaca, temple bagian depan kaca dengan plester penutup. Ini akan menyatukan potongan kaca; seandainya pecahpun akan mengurangi resiko kerusakan pada karya.

4. Lukisan tanpa stretcher ataupun frame yang berukuran besar perlu digulung untuk dibawa dan dipindahkan. Pada saat menggulung, sangat penting bahwa lukisan digulung dengan cara yang benar — bagian bergambar di sisi luar- dan disisipi lembaran kosong serta penggulung diberi bantalan secukupnya. Bila lapisan cat berada di bagian dalam pada saat lukisan digulung, cat akan tertekan dan menimbulkan lipatan yang akan tetap tertinggal pada lukisan setelah gulungan dibuka. 


\subsection{Teknik Membingkai Lukisan}

Bingkai adalah alat perlindungan yang penting bagi lukisan. Jika memungkinkan, lukisan perlu diberi perlindungan di bagian depan dan belakang dari kerusakan akibat:

1. benturan dan goresan;

2. debu dan polusi;

3. perubahan atau ketidakstabilan kondisi lingkungan; dan

4. hama-hama biologis.

Diagram berikut (Gb.4) memperlihatkan bagaimana lukisan kanvas dengan stretcher harus dipaskan pada bingkai untuk memberikan lingkungan yang terlindung bagi lukisan.

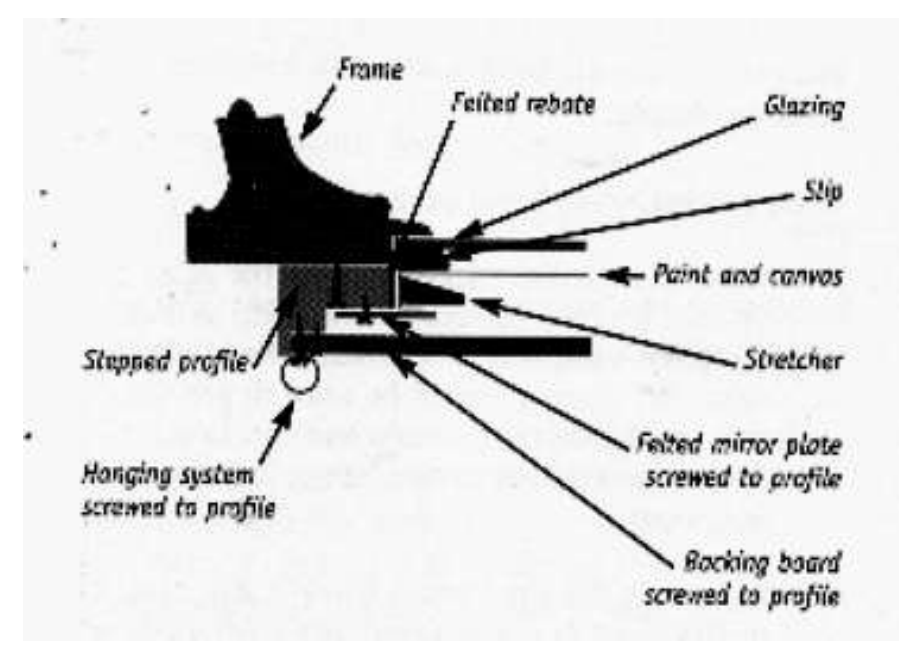

Gambar 4 Diagram potongan pemasangan lukisan pada bingkai. (Sumber: Heritage Collections Council, 1998) [4]

\subsection{Cara Menggantung Lukisan}

Terdapat dua prinsip utama yang harus diperhatikan pada saat menggantung lukisan:

1. Karya harus disangga dengan baik sesuai bobotnya.

2. Tidak boleh ada tekanan pada setiap bagian lukisan atau sistem penggantung.

Beberapa prinsip dasar yang perlu diperhatikan:

1. Menggunakan material yang tidak akan berkarat. 
2. Memastikan bahwa dinding tempat menggantung dalam kondisi stabil dan kuat secara struktural

3. Memastikan bahwa tekanan selalu terbagi rata di seluruh karya.

4. Tidak menggantung lukisan pada 1 titik tumpu.

\subsection{Memahami Kondisi Ideal untuk Menggantung dan Menayangkan Lukisan}

Berdasarkan eksperimen yang dilakukan, idealnya, lukisan disimpan di lingkungan :

1. Memiliki suhu tetap dan sedang, berkisar antara $18-20^{\circ}$ C. Jika di tempat tersebut suhu secara umum di luar batas tersebut, cobalah untuk memastikan bahwa perubahannya tidak cepat dan pertahankan di suhu minimum.

2. Kelembaban relatif berkisar antara $45-55 \%$. Hal ini penting bagi lukisan karena sebagian besar komponennya sensitif-lembab, dan kelembaban relatif yang tinggi dapat menyebabkan kerusakan secara fisik. Perubahan kelembaban relatif harus diupayakan seminimum mungkin dan tidak cepat. Perubahan kelembaban relatif akan mengakibatkan sejumlah perubahan ukuran dan memisahkan cat dari lapisan dasar struktur lukisan.

3. Minimalkan pemakaian lampu dalam melakukan aktivitas. Jika memungkinkan, simpan lukisan di tempat yang relatif gelap. Hal ini akan memperkecil resiko pudar dan lunturnya komponen-komponen tertentu yang sensitif dari sebuah lukisan.

\section{Simpulan}

Praktik seni lukis di Studio Seni Lukis FSRD-ITB secara umum masih dipandang hanya sebagai medium belajar mengekspresikan gagasan saja, belum sampai pada kesadaran bahwa lukisan tersebut juga mewakili sebuah gagasan manusia sesuai semangat zaman (zeitgeist) tertentu. Hal ini dapat dijumpai pada teknik penyimpanan lukisan, dokumentasi dan pengelolaan koleksi serta aspekaspek pencegahan terhadap kerusakan lukisan yang masih belum menjadi kesadaran kolektif, khususnya bagi mahasiswa.

Konservasi preventif sebaiknya diberikan pada mahasiswa dengan harapan merupakan sebuah bentuk kegiatan yang paling realistis dalam konteks mahasiswa saat ini karena tidak terlalu membutuhkan biaya yang besar untuk melaksanakannnya (pertimbangan aspek ekonomis). Disamping itu, aspek lain yang jauh lebih penting adalah menanamkan sikap akan pentingnya upaya pencegahan sebagai konsekuensi logis dari kesadaran terhadap pentingnya artefak lukisan bagi kebudayaan. 
Dalam konteks pragmatis, kesadaran konservasi ini sebaiknya dilaksanakan dalam bentuk workshop yang secara sistematis dan berkesinambungan dapat diberikan kepada mahasiswa seni rupa dan pihak pengelola galeri serta museum, sehingga kasus-kasus spesifik dari tiap galeri misalnya dapat dijadikan contoh. Bentuk lain adalah materi konservasi ini juga dapat disampaikan atau menjadi bagian yang integral (disisipkan) pada salah satu perkuliahan teoritis di kelas, sehingga aspek-aspek normatif dari konservasi sudah mahasiswa ketahui sejak awal.

Dengan upaya-upaya di atas diharapkan konservasi dapat menjadi suatu kebiasaan dan sikap yang dapat ditanamkan paling tidak pada tingkat profesi (seni lukis) —walaupun belum bisa dilaksanakan pada tingkat pendidikan dasar- yang diharapkan dapat mendukung kualitas dari karya secara keseluruhan. Pada tingkat yang lebih jauh juga diharapkan dapat membantu perkembangan lembaga-lembaga kolektor seperti museum dan galeri.

\section{Referensi}

[1] Feldman, Edmund Burke. 1967. Art as Image and Idea, New Jersey: Prentice-Hall, Inc, hal 308.

[2] Hayman, d'Arcy. 1969. Introduction dalam The Arts and Man: A World View of the Role and Functions of the Arts in Society, France: Unesco.

[3] Heritage Collections Council. 1998. Caring for Cultural Material, Australia: the Commonwealth Department of Communications, Information Technology and the Arts, hal 10.

[4] Heritage Collections Council. 1998. Damage and Decay, Australia: the Commonwealth Department of Communications, Information Technology and the Arts, hal 26. 